\title{
Análise do potencial teórico da geração de energia a partir do biogás no aterro sanitário de Varginha/MG
}

As cidades brasileiras enfrentam problemas com o destino dos resíduos sólidos urbanos, pois esses ainda são despejados em grandes quantidades em lixões sem nenhum tipo de tratamento. Nos aterros sanitários, o uso do biogás na geração de energia elétrica se tornou uma maneira sustentável de se aproveitar energeticamente os resíduos sólidos, e que ainda tem como vantagem a redução nas emissões dos gases de efeito estufa. Neste contexto, este artigo tem como objetivo avaliar o possível potencial do uso do biogás para geração de energia elétrica no aterro sanitário na cidade de Varginha/MG. O aterro sanitário hipotético geraria 1,32 MW por ano ao receber uma média de 701,84ton de resíduos por dia. A análise financeira revela que o projeto é viável, mas depende das receitas geradas pela comercialização de créditos de carbono.

Palavras-chave: Resíduos sólidos urbanos; Aterro sanitário; Biogás; Geração de energia elétrica.

\section{Analysis of the theoretical potential of biogas energy generation in the Varginha/MG sanitary landfill}

Brazilian cities face problems with the destination of solid urban waste, since these are still dumped in large quantities in dumps without any type of treatment. In landfills, the use of biogas in the generation of electricity has become a sustainable way to take advantage of solid waste, and still has the advantage of reducing the emissions of greenhouse gases. In this context, this article aims to evaluate the potential potential of the use of biogas for electricity generation in the sanitary landfill in the city of Varginha (MG). The hypothetical landfill would generate $1.32 \mathrm{MW}$ per year by receiving an average of 701.84ton of waste per day. The financial analysis reveals that the project is feasible but depends on the revenues generated by the commercialization of carbon credits.

Keywords: Urban solid waste; Landfill; Biogas; Generation of electric energy.

Topic: Engenharia Ambiental

Reviewed anonymously in the process of blind peer.
Received: 07/07/2017

Approved: 09/10/2017
Erika Barrak

Universidade Federal de Itajubá, Brasil http://lattes.cnpq.br/3570412221275580 erikabarrak@gmail.com
Referencing this:

BARRAK, E.. Análise do potencial teórico da geração de energia a partir do biogás no aterro sanitário de Varginha/MG. Natural Resources, v.7, n.1, p.61-72, 2017. DOI: http://doi.org/10.6008/SPC2237$\underline{9290.2017 .001 .0007}$ 


\section{INTRODUÇÃO}

Os resíduos sólidos urbanos (RSU) atualmente são um problema nos centros urbanos, visto que nas últimas décadas houve um aumento nas atividades industriais e aumento da população. Com o crescimento desordenado e sem planejamento das cidades, o manejo dos resíduos sólidos urbanos se torna uma dificuldade. Estes são despejados em locais não apropriados, como por exemplo, em lixões, que são depósitos a céu aberto, que por não apresentarem nenhum tipo de tratamento ou controle nos resíduos sólidos ali despejados, oferecem risco à saúde e ainda prejudicam o meio ambiente contaminando o solo, ar e água. Uma das soluções para reduzir a quantidade de lixo depositado nos lixões e que será o motivo de estudo deste artigo é a utilização deles como combustível para geração de energia elétrica na busca por fontes de energias alternativas.

Em relação à disposição final dos resíduos, segundo a ABRELPE (2015), 58,7\% dos resíduos coletados foram encaminhados para os aterros sanitários, enquanto que cerca de 30 milhões de toneladas de resíduos foram dispostos em lixões ou aterros controlados, elevando o potencial de poluição ambiental e riscos à saúde, já que ambos não tratam dos resíduos ali dispostos. No Brasil a destinação inadequada dos resíduos sólidos ainda é muito presente em todas as regiões e estados brasileiros e em 3.326 municípios. O Norte é a região onde mais da metade dos municípios (54\%) ainda utilizam o lixão como destinação final dos RSU.

Segundo Tolmasquim (2003), a busca por tecnologias alternativas para o aproveitamento dos resíduos sólidos urbanos se mostra de extrema importância, devido principalmente à falta de áreas para a disposição final de resíduos que se encontram próximos aos centros urbanos, devido ao potencial de aproveitamento energético apresentado pelo lixo urbano brasileiro e à redução de emissões de gases efeito estufa. Estes são motivos suficientes para busca de novas tecnologias que resolvessem essas três questões simultaneamente, de forma ambientalmente correta, com viabilidade técnica e econômica.

Desta maneira, o objetivo deste artigo será estimar o potencial teórico da geração de energia elétrica a partir da queima do biogás de um aterro sanitário hipotético para a cidade de Varginha-MG e realizar uma análise econômica considerando ferramentas financeiras como VPL, TIR, LCOE. Payback.

\section{REVISÃO TEÓRICA}

Uma das formas de se gerar energia pela utilização dos resíduos sólidos urbanos é através do aproveitamento do biogás gerado nos aterros sanitários. De acordo com Borba (2006) um aterro pode ser comparado a um reator biológico, onde as principais entradas são os resíduos e a água e as principais saídas são os gases e o chorume. A decomposição da matéria orgânica ocorrerá em dois processos, o primeiro é de decomposição aeróbia e ocorre normalmente no período de deposição do resíduo. Após este período, a redução do $\mathrm{O}_{2}$ presente nos resíduos dá origem ao processo de decomposição anaeróbia. De acordo com Tchobanoglous et al. (1993), a formação e a taxa de geração dos principais constituintes do gás de aterro variam ao longo do tempo e segue diferentes etapas que serão descritas a seguir:

Fase I: A primeira fase é da decomposição aeróbia da matéria orgânica, devido à presença de oxigênio contido no interior do aterro. Nesta etapa, a terra que é usada 
como material de cobertura no aterro é a principal fonte de microrganismos para a decomposição aeróbia. As bactérias aeróbias consomem oxigênio enquanto metabolizam as cadeias de carboidratos complexos, proteínas e lipídeos contidos nos resíduos orgânicos. $\mathrm{O}$ primeiro gás a ser produzido é o $\mathrm{CO}_{2}$, enquanto uma grande quantidade de $\mathrm{N}_{2}$ declina rapidamente no decorrer do processo (GONÇALVES, 2013);

Fase II: Fase em que o oxigênio é consumido e inicia-se o desenvolvimento das condições anaeróbias. Enquanto o aterro se converte em anaeróbio, o nitrato e o sulfato que podem servir como aceptores de elétrons em reações de conversão biológica são frequentemente reduzidos a gás nitrogênio e gás sulfídrico. Nesta fase o ambiente se torna totalmente ácido, devido às bactérias que convertem os compostos criados pelas bactérias aeróbias em ácido acético, lático, fórmico e álcoois, como metano e etanol. Os gases formados nesta etapa são o dióxido de carbono e hidrogênio;

Fase III: caracterizada como ambiente anaeróbio, esta fase se inicia quando certas bactérias consomem os ácidos gerados na fase anterior formando o acetato, um ácido orgânico. Há o estabelecimento das bactérias metanogênicas devido ao ambiente desta fase se tornar neutro. Estas bactérias consomem o carbono e o acetato, dando o início para a produção de metano e redução da quantidade de dióxido de carbono;

Fase IV: última etapa, a qual se inicia quando a taxa de composição e produção do gás de aterro se mantém praticamente constante. Nesta fase o gás de aterro contém, em volume, $45 \%$ a $60 \%$ de metano, de $30 \%$ a $60 \%$ de dióxido de carbono e de $2 \%$ a $5 \%$ de outros gases, sendo estes o oxigênio, nitrogênio, gás sulfídrico amônia e hidrogênio.

O metano e o dióxido de carbono são os principais gases provenientes da decomposição anaeróbia dos compostos biodegradáveis dos resíduos orgânicos. A conversão do biogás em energia elétrica pode ser realizada por meio de motores de combustão interna, turbinas a gás e microturbinas a gás. A utilização dos motores de combustão interna para conversão de energia é a mais utilizada e isso se deve ao fato de apresentarem maior rendimento elétrico, entre $30 \%$ e $40 \%$, possuírem baixo custo e é a tecnologia mais difundida em relação às outras.

\section{METODOLOGIA}

A metodologia aplicada neste artigo consistiu em realizar a projeção populacional e estimar geração de resíduos sólidos urbanos de Varginha durante 20 anos, período em que o aterro receberá os resíduos sólidos urbanos e através do software LandGEM ${ }^{\circ}$ (USEPA, 2005), software que quantifica as emissões devido à decomposição dos RSU no aterro. obteve-se o potencial de produção de biogás ao longo desses 20 anos. A partir da quantidade de gás gerado foi realizado o planejamento energético da geração de energia através de motores de combustão interna Otto e em seguida foi feita uma análise econômica para o projeto através das ferramentas financeiras VPL (valor presente líquido) e TIR (taxa interna de retorno). 


\section{Projeção da população e geração de resíduos sólidos}

Tabela 1: População dos últimos três censos do IBGE.

\begin{tabular}{cc} 
Ano & População \\
\hline 2000 & 108.998 \\
2007 & 116.093 \\
2010 & 123.081 \\
\hline
\end{tabular}

Para a projeção populacional é necessário que se conheça ao menos três dados sobre a população do município escolhido. Através do site do IBGE foi possível obter os dados da série histórica da população de Varginha dos anos 2000, 2007 e 2010, que são apresentados na tabela 1. O cálculo da projeção foi feita no software Microsoft ${ }^{\circledR}$ Excel e a metodologia utilizada foi a de Qasim (1985, citado por VON SPERLING, 2005). Para o cálculo, foi adotado o crescimento logístico para projeção populacional, modelo matemático em que o crescimento populacional segue uma relação matemática em que população tende assintoticamente a um valor de saturação (Ps). Através das equações de 1 a 4 , calcula-se a população $\left(P_{t}\right)$ para cada ano:

$$
\begin{gathered}
K_{s}=\frac{2 . P_{0} \cdot P_{1} \cdot P_{2}-P_{1}^{2} \cdot\left(P_{0}+P_{2}\right)}{P_{0} \cdot P_{2}-P 1_{1}^{2}} \\
a_{1}=\frac{1}{t_{2}-t_{1}} \cdot \ln \frac{P_{0} \cdot\left(K_{s}-P_{1)}\right.}{P_{1} \cdot\left(K_{s}-P_{0}\right)} \\
c=\frac{K_{s}-P_{0}}{P_{0}} \\
P_{t}=\frac{K_{s}}{1+c \cdot e^{a_{1} \cdot\left(t-t_{0}\right)}}
\end{gathered}
$$

$\mathrm{K}_{\mathrm{s}}=$ coeficiente de capacidade de saturação; $\mathrm{P}_{0}, \mathrm{P}_{1}, \mathrm{P}_{2}$ e $\mathrm{P}_{\mathrm{t}}$ = população no tempo to, população no tempo $\mathrm{t}_{1}$, população no tempo $t_{2}$ e população estimada para cada ano.

\section{Geração de resíduos sólidos urbanos}

O cálculo da geração dos resíduos, que pode ser visto na equação 5 , foi feito a partir do índice de geração per capita de massa coletada no ano de 2010 para a cidade de Varginha, cujo valor foi de 0,65 $\mathrm{kg} / \mathrm{hab} /$ dia (FERREIRA, 2013) com acréscimo de 1\% para os anos seguintes (BARROS, 2012).

$$
G_{R S U}=P_{t} \cdot G_{\text {per capita }} \cdot 365
$$

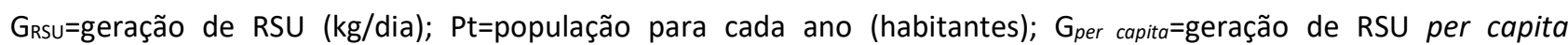
(kg/hab.dia); 365=número de dias no ano.

\section{Software LandGEM ${ }^{\circ}$}

O LandGEM ${ }^{\circ}$, (Landfill Gas Emissios Model-Modelo de Emissão de Gases de Aterro Sanitário), software da United States Environmental Protection Agency (USEPA, 2005), é uma ferramenta de estimativa com interface do Microsoft Excel que pode ser usado para estimar as taxas de emissões de gás total do aterro, metano, dióxido de carbono, compostos orgânicos não metano e os poluentes atmosféricos individuais de aterros sanitários de resíduos sólidos. O LandGEM $^{\circledR}$, utiliza a equação de primeira ordem, conforme a equação 6 proposta, para estimar a taxa de emissões pela decomposição anual em relação a um período especificado pelo usuário. Segue abaixo os parâmetros de entrada no software LandGEM ${ }^{\circledR}$. 


$$
Q_{C H 4}=\sum_{i=1}^{n} \sum_{j=0,1}^{1} K L_{0}\left(\frac{M_{t}}{10}\right) e^{-K t_{i, j}}
$$

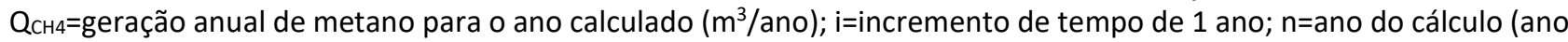
inicial de abertura do aterro); j=incremento do tempo de 0,1 ano; k=capacidade potencial de geração de metano (ano$\left.{ }^{1}\right)$; $L_{0}=$ capacidade potencial de geração de metano $\left(\mathrm{m}^{3} / \mathrm{Mg}\right) ; \mathrm{Mt}_{\mathrm{t}}=$ massa de resíduos aceita no enésimo ano ( $\mathrm{Mg}$ );

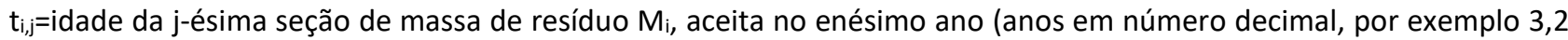
anos).

Tabela 2: Parâmetros adotados no software.

\begin{tabular}{lcc}
\multicolumn{1}{c}{ Parâmetros } & Valores & Fonte \\
\hline Taxa de geração de metano $(\mathrm{k})\left(\right.$ ano $\left.^{-1}\right)$ & 0,5 & \\
Capacidade potencial de geração de metano $\left(\mathrm{L}_{0}\right)\left(\mathrm{m}^{3} / \mathrm{Mg}\right)$ & 170 & USEPA (2005) \\
Porcentagem de metano contido no biogas $(\%)$ & 50 & \\
\hline
\end{tabular}

\section{Cálculo da potência disponível}

O cálculo para estimar a potência disponível através do biogás gerado pela decomposição da matéria orgânica do aterro sanitário é dada a partir da equação 7, ilustrado na tabela 6 . Foi adotado que $75 \%$ do biogás gerado é coletado (CETESB, 2006). Logo em seguida, tem-se a conversão de metano em energia para cada ano, que é calculada através da equação 8.

$$
P_{\text {disp }}=\frac{Q \cdot E C \cdot P C I . \eta}{31.536 .000}
$$

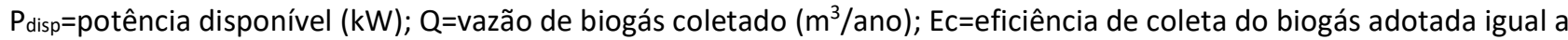
75\% (CETESB, 2006); $\eta=$ rendimento do motor de combustão interna operando em plena carga, 33\%; $\mathrm{PCl}=$ poder calorífico inferior do biogás $\left(\mathrm{kJ} / \mathrm{m}^{3}\right) ; 31.536 .000=$ tempo de operação (s) (CETESB, 2006).

$$
E=P_{\text {disp }} . t
$$

$\mathrm{E}=$ Potência elétrica útil $(\mathrm{kW})$; Pdisp=Potência disponível $(\mathrm{kW})$; $\mathrm{t}=$ número de horas de operação anual. Valor adotado 8.000 horas.

\section{Planejamento energético}

Uma vez que a curva da potência do aterro é variável, se torna importante para a análise do investimento econômico que seja definido um valor de potência por um determinado período. Foi adotado que os grupos geradores operarão a plena carga, ou seja, operarão no limite de sua potência nominal de acordo com a potência disponível do aterro associada à vazão de biogás. Também se adotou a utilização de mais de um grupo gerador, que serão substituídos sequencialmente e que operarão por curtos períodos, entre 5 e 8 anos. Em seu trabalho Leme et al. (2014) adotou a utilização de 9 grupos geradores de mesma potência cujo tempo de operação de cada motor foi de 7 anos devido aos problemas de corrosão associados ao sulfeto presente no biogás, que acarreta a diminuição da vida útil dos motores.

\section{Análise financeira}

As ferramentas matemáticas de análise econômica servem para auxiliar o investidor na tomada de decisão de um projeto ser economicamente atrativo ou não. Para este trabalho serão utilizados o Valor Presente Líquido (VPL), Taxa Interna de Retorno (TIR), Payback Descontado. 


\section{Valor Presente Líquido}

Em um projeto o Valor Presente Líquido (VPL) é o valor presente de suas entradas futuras de caixa menos o valor presente do investimento inicial e das saídas futuras de caixa. A Taxa Mínima de Atratividade (TMA) é utilizada como taxa de desconto no cálculo do valor presente das entradas e saídas de caixa. O valor adotado para TMA foi de $12 \%$ a.a. A seguir são descritas as possibilidades para o VPL:

VPL > 0: significa que o valor presente das entradas de caixa é maior que o presente das saídas de caixa, portanto o investimento do projeto é economicamente viável.

VPL = 0: significa que o investimento é economicamente atrativo, pois o retorno esperado do projeto é iguala à TMA exigida pelos investidores.

$\mathrm{VPL}<0$ : significa que o valor presente das entradas é menor do que o valor presente das saídas, logo o investimento não se torna economicamente atrativo.

A equação do VPL pode ser calculada através da equação 9.

$$
V P L=I+\sum_{t=1}^{N} \frac{F C_{t}}{(1+i)^{t}}
$$

\section{Taxa Interna de Retorno}

A Taxa Interna de Retorno (TIR) faz com que o VPL seja igual a zero, ou seja, a TIR é a taxa de desconto que faz com que o valor presente de entrada de caixa seja igual ao de saída. A seguir são descritas as possibilidades para a TIR:

TIR > TMA: o investimento é economicamente viável, pois a taxa de retorno esperada supera a taxa mínima de atratividade exigida para a implantação do projeto.

TIR = TMA: a taxa de retorno do projeto é igual à taxa mínima de atratividade e, portanto, o investimento é considerado atrativo.

TIR < TMA: a taxa de retorno esperada é inferior à taxa mínima de atratividade desejada pelos investidores.

$$
V P L=0=I+\sum_{t=1}^{N} \frac{F C_{t}}{(1+T I R)^{t}}
$$

\section{Payback Descontado}

O payback descontado visa quantificar o período em que um investimento é recuperado através dos fluxos de caixa após a realização do desembolso inicial. Ao contrário do payback simples, o payback descontado considera o valor do dinheiro no tempo, ou seja, o payback descontado é o tempo de recuperação do investimento, remunerado pela taxa de juros representada pela TMA.

$$
P D=\sum_{\mathrm{k}=1}^{\mathrm{j}} \frac{\mathrm{FC}_{\mathrm{k}}}{(1+\mathrm{TMA})^{\mathrm{k}}}
$$

\section{Parâmetros adotados para análise financeira}

A análise financeira para o projeto de geração de energia através do biogás foi baseada no fluxo de caixa, que inclui o investimento inicial, receitas e despesas com operação e manutenção (O\&M). $O$ investimento inicial considera a compra e instalação dos componentes relacionados ao sistema de coleta, flare para queima do gás excedente, condicionamento do gás e tratamento e o sistema de geração de energia 
que inclui os grupos geradores. Os custos dos componentes necessários para geração de energia do aterro sanitário. A correção dos valores dos custos da tabela 11, que são dados do ano de 1997, foram corrigidos através das equações 11 e 12 .

$$
\begin{gathered}
\mathrm{IC}=\left(1+\frac{i_{t}}{100}\right) \cdot\left(1+\frac{i_{t}}{100}\right) \cdot \ldots \cdot\left(1+\frac{i_{t}}{100}\right) \\
\mathrm{C}_{\text {corrigido }}=V_{\text {inicial }} \cdot\left(I C+V_{\text {inicial }}\right)
\end{gathered}
$$

\begin{tabular}{|c|c|}
\hline \multicolumn{2}{|c|}{ Sistema de coleta } \\
\hline Componentes & Custos (US\$) \\
\hline Poços & $400,86 / \mathrm{m}$ de profundidade \\
\hline Cabeçotes & $1.147,5 /$ unidade \\
\hline Tubulação & $175,95 / \mathrm{m}$ \\
\hline Soprador & $1.080,18 / \mathrm{m}^{3} /$ minuto \\
\hline Remoção de condensado & $12.240 /$ unidade \\
\hline Sistema de monitoramento & 1.530/unidade \\
\hline \multicolumn{2}{|l|}{ Flare } \\
\hline Flare & 114.750/unidade \\
\hline \multicolumn{2}{|c|}{ Condicionamento do gás/tratamento } \\
\hline Lavador & $810,9 / \mathrm{m}^{3} /$ minutos \\
\hline Desumidificador & $540,04 / \mathrm{m}^{3} /$ minutos \\
\hline Refrigeração & $3.240,54 / \mathrm{m}^{3} /$ minutos \\
\hline Filtros & 4.896/unidade \\
\hline Instalação de tratamento do gás e outros custos & $810,9 / \mathrm{m}^{3} /$ minutos \\
\hline \multicolumn{2}{|c|}{ Geração de eletricidade } \\
\hline Sistema de controle & $229,5 / \mathrm{kW}$ \\
\hline Instalação da geração de eletricidade e outros custos & $612 / \mathrm{kW}$ \\
\hline Grupo moto-gerador (baixa e alta pressão) & $688,5 / \mathrm{kW}$ \\
\hline
\end{tabular}

Tabela 03: Custo do investimento para os sistemas básicos para geração de energia a partir do biogás de aterro.

Fonte: USEPA, 1997.

$$
N_{D}=\frac{A_{A}}{\pi \cdot R^{2}}
$$

Para o projeto é necessário saber o número de drenos que serão usados no sistema de coleta. Através da fórmula 12, predisposta na tabela 12 , há a fórmula na qual se obtém esta quantidade. De acordo com Monteiro (2001) para se estimar a área total do aterro, em $\mathrm{m}^{2}$, multiplica-se a quantidade de lixo coletado diariamente, em toneladas, pelo fator 560 . Este fator se baseia em parâmetros utilizados em projetos de aterro com: 20 anos de vida útil, 20 metros de altura do aterro, talude $1: 3$ e $80 \%$ do terreno ocupado com a área operacional. Os valores da altura do poço e comprimento da tubulação foram adotados como sendo de $15 \mathrm{~m}$ e $500 \mathrm{~m}$ respectivamente. As receitas obtidas no projeto foram a venda de energia elétrica e a comercialização dos créditos de carbono que podem ser calculados através das equações 12 e 13 , respectivamente:

$$
\begin{gathered}
E_{e l}=E \cdot \mathrm{C}_{\mathrm{el}} \\
C C=Q_{C H 4} \cdot 0,000679 \cdot 21 \cdot(1-F A)
\end{gathered}
$$

O preço da energia elétrica utilizado foi o valor de R\$235,95/MWh obtido no leilão de energia nova (A-5) para empreendimentos de biomassa do ano de 2016 (ANEEL, 2016). O valor adotado para conversão em dólares foi o cotado pelo Banco Central Brasileiro do dia 17/02/2017 no valor de $\mathrm{R} \$ 3,0499$. O preço 
adotado para o crédito de carbono foi de $€ 4,94$ na data 17/02/2017, cuja cotação do euro para esta dada de acordo com o Banco Central Brasileiro foi de US\$1,07. As despesas com operação e mão de obra estão listadas na tabela 04.

Tabela 02: Custo de O\&M.

\begin{tabular}{cc}
\hline \multicolumn{2}{c}{ Sistema de coleta } \\
\hline O\&M & Flare \\
\hline O\&M & $3.530 /$ poço/ano \\
\hline O\&M & Condicionamento do gás/tratamento \\
\hline O\&M & Geração de eletricidade \\
\hline Os custos foram corrigidos através do índice de correção de 53\% entre 1997 e 2016. \\
\hline
\end{tabular}

Fonte: USEPA, 1997.

\section{Resultados}

\section{Estimativa populacional e geração de resíduos sólidos urbanos}

A partir dos dados da população dos anos de 2000, 2007 e 2010 obtidos pelo site IBGE cidades , conforme proposto anteriormente pela tabela 1 e da metodologia de crescimento logístico, obteve-se a projeção populacional e a estimativa da quantidade de resíduos gerados na cidade de Varginha durante os 20 anos de funcionamento do aterro sanitário hipotético, de acordo com a figura 1.

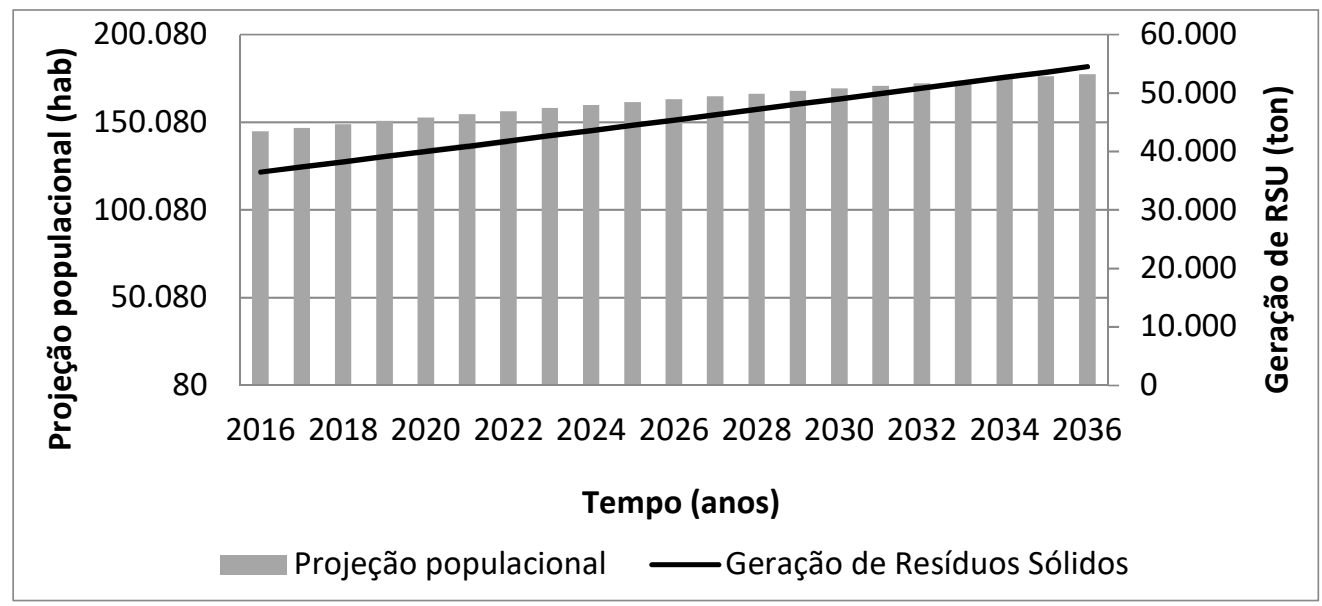

Figura 1: Estimativa do crescimento populacional e da geração de resíduos de Varginha.

\section{Estimativa da geração de biogás de aterro}

A quantidade de resíduos sólidos urbanos gerados anualmente serviu de entrada no software LandGEM $^{\circ}$ para estimar quanto de biogás e metano serão produzidos pelo aterro. Na figura 2 estão representadas as curvas de biogás e metano gerados no aterro, onde a produção de gás aumenta conforme mais resíduos são depositados no aterro, com o passar dos anos, até que essa produção de gás chega ao seu máximo valor de $10,43.10^{6} \mathrm{~m}^{3} /$ ano, que corresponde ao último ano de funcionamento do aterro. A partir deste ponto a curva decai, uma vez que o aterro já não recebe RSU e pela recalcitrância microbiana, ou seja, a incapacidade dos microrganismos na degradação e reciclagem de nutrientes. De acordo com Souza (2005) 
esta dificuldade de degradação biológica pode estar associada a presença de compostos de elevada massa molecular com estruturas complexas.

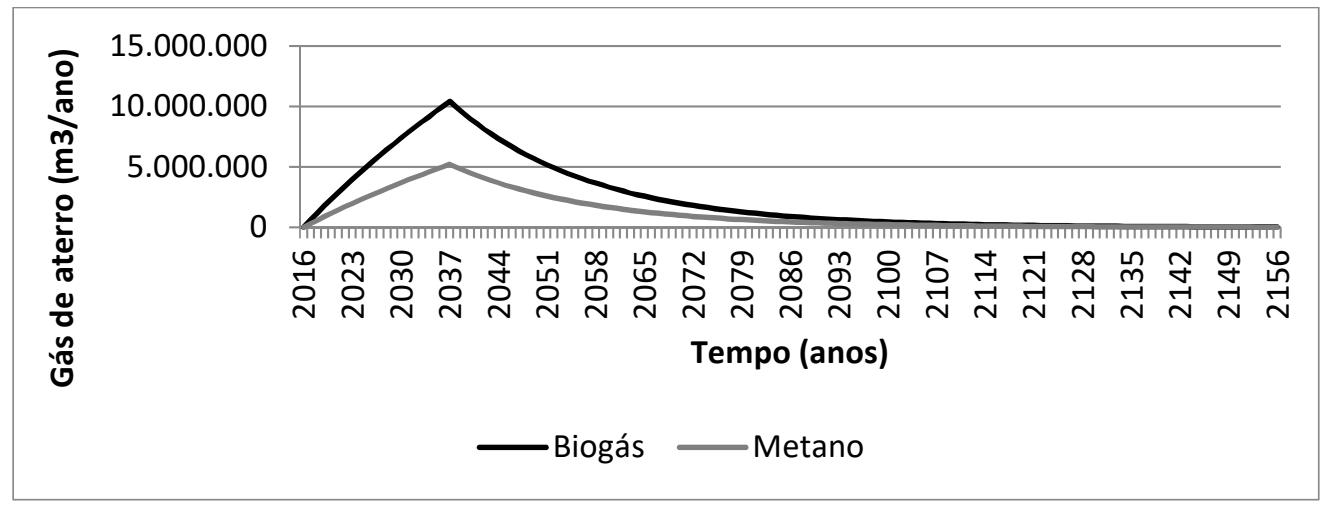

Figura 2: Produção de biogás e metano no aterro de Varginha.

A partir dos valores anuais de biogás obtidos pelo software LandGEM $^{\circledR}$, a potência e energia disponível para cada ano foi calculada através das equações 7 e 8, respectivamente. As estimativas da potência e da energia elétrica disponível podem ser vistas na figura 3. Ambas aumentam com o passar dos anos até 2037, já que estes valores estão associados à geração de biogás. Se considerar que a média mensal de consumo de energia de uma casa é 250 kWh e através dos cálculos realizados, a energia média disponível por ano gerada pelo aterro corresponde a 1.024.315 kWh, estima-se que com esta energia seria possível abastecer aproximadamente 4.100 residências.

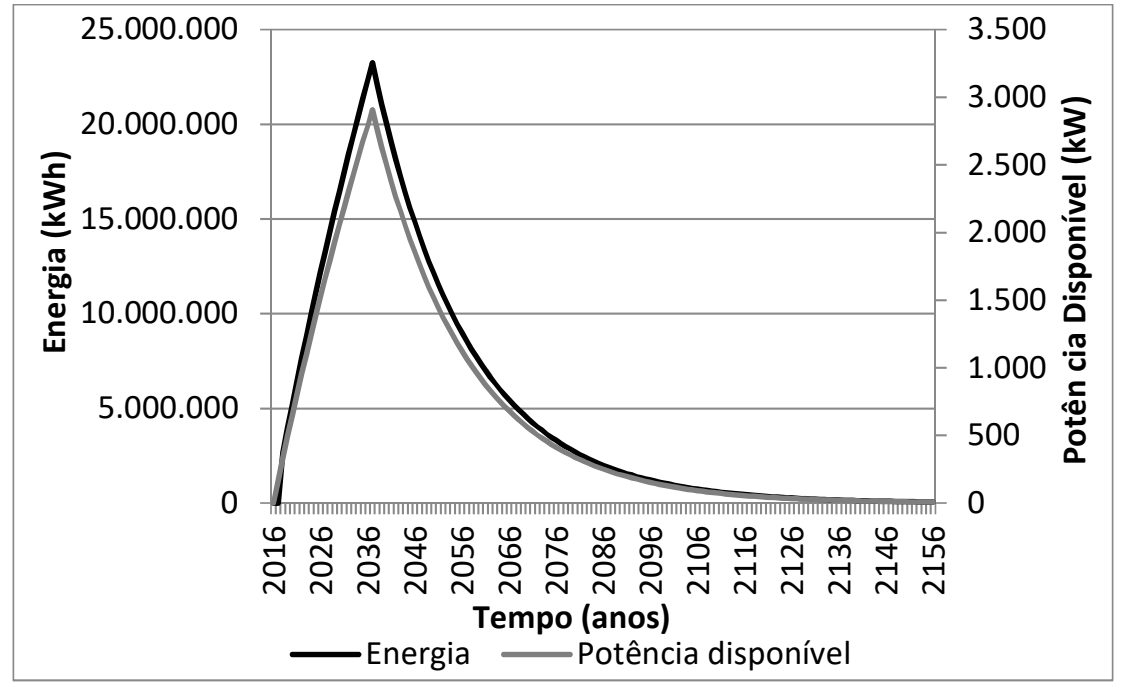

Figura 3: Potência disponível e energia.

\section{Planejamento energético}

A partir da potência disponível do aterro, foi selecionado o primeiro grupo gerador de potência de 500 kW, que começará a operar a partir do quarto ano (2019) da abertura do aterro até 2023, ano em que um novo grupo gerador de potência de 1.200 kW será adquirido e operará por 6 anos. E por fim em 2030 será posto em operação o grupo gerador de $2.000 \mathrm{~kW}$ que gerará energia até o vigésimo primeiro ano de 
operação do aterro. O planejamento energético com a utilização de 3 grupos geradores pode ser observado na figura 4.

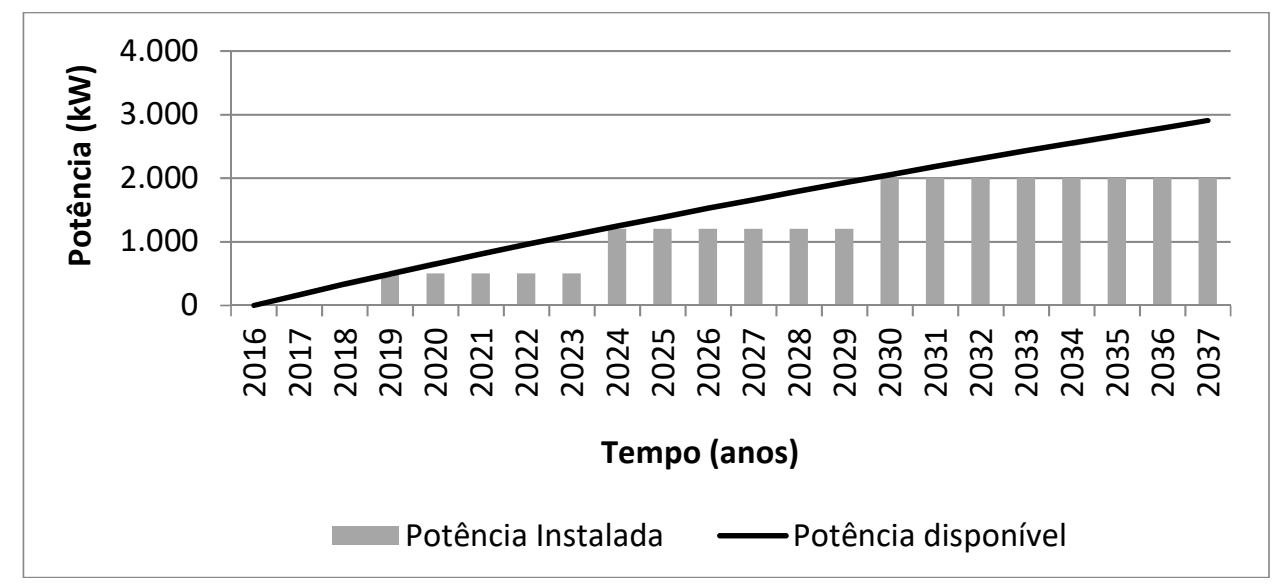

Figura 4: Planejamento energético

Em 20 anos o aterro acumula uma energia disponível de 270.419 .298 kWh. A partir do planejamento energético realizado com o uso dos motores de combustão interna para geração de energia elétrica e considerando seu funcionamento durante 8.000 horas ao ano, $76 \%$ da energia total disponível do aterro será convertida em energia elétrica, gerando 1,32 MW de potência. Pode não se tratar de um grande potencial, mas pode ser visto com uma estratégia local ou regional gerar energia elétrica a partir do aterro sanitário.

\section{Análise financeira}

A partir dos valores anuais de geração de RSU e considerando que $100 \%$ do lixo gerado é coletado, conclui-se que são enviados para o aterro uma média de 701,84 t/dia de RSU distribuídos em uma área total de $393.030 \mathrm{~m}^{2}$, cuja coleta de biogás será realizada por 50 drenos. A figura 5 representa o investimento, as receitas e despesas consideradas neste trabalho para a análise financeira. $\mathrm{O}$ investimento inicial da planta foi de $(\$ 1.418 .504,67)$. As receitas geradas pela venda de energia foram de $\$ 305.002,59$ com a utilização do motor de $500 \mathrm{~kW}, \$ 732.006,20$ para o motor de $1.200 \mathrm{~kW}$ e $\$ 1.220 .010,34$ para o motor de $2.000 \mathrm{~kW}$. Já a receita relacionada à comercialização de créditos de carbono foi variável e crescente, devido a geração de biogás que aumenta com o passar dos anos.

O projeto se mostrou viável e apresentou VPL positivo no valor de $\$ 1.169 .783,30$ e TIR de $19 \%$, com retorno de investimento previsto a partir do décimo sexto ano. Para avaliar a importância dos parâmetros adotados para a realização da análise econômica, foi feito uma análise de sensibilidade variando $\pm 50 \%$ o preço da energia elétrica, o preço para comercialização dos créditos de carbono e o valor do investimento inicial. 


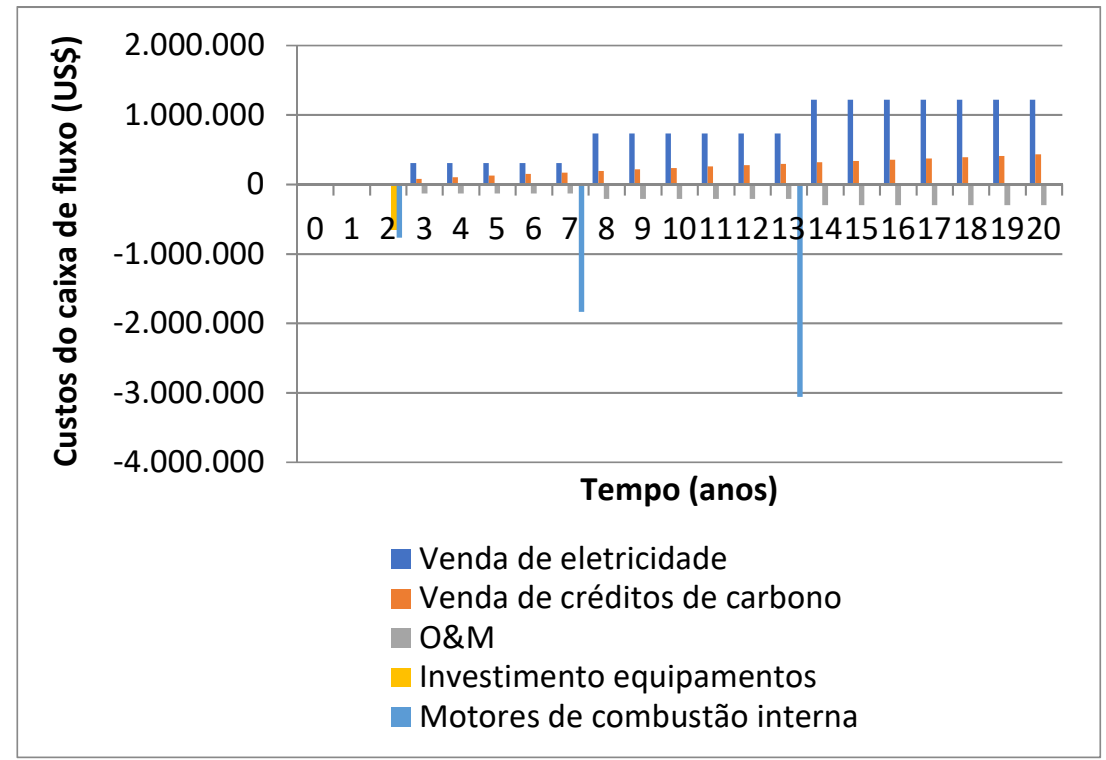

Figura 5: Custos que formam o caixa de fluxo.

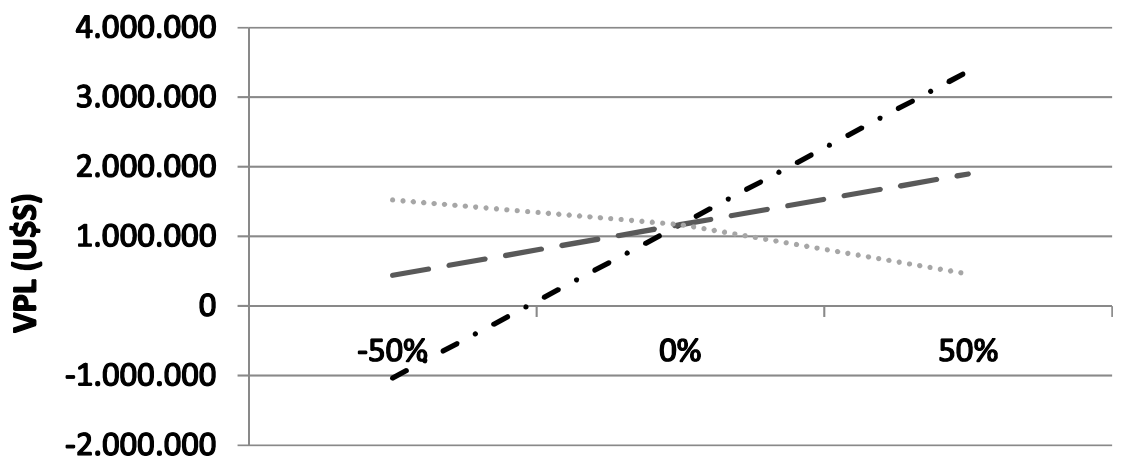

\section{- - Preço energia - - Preço tCO2 ….... Investimento}

Figura 6: Análise de sensibilidade

Ao observar a figura 6, dentre as curvas que possuem maior inclinação em relação ao eixo horizontal é a curva relacionada ao preço da venda de energia, que causa um impacto negativo em relação à viabilidade do projeto no caso de haver uma redução de $50 \%$ em seu valor, o que inviabilizaria o projeto $(\mathrm{VPL}<0)$. 0 preço mínimo de venda da energia (VPL=0) é de \$56,01 e sabe-se que segundo dados da Aneel (2016), entre os anos de 2005 e 2016 os preços da energia elétrica nos leilões de energia nova (A-5) variaram desde o menor valor de ${ }^{1} \$ 33,31$ em 2011 , até o mais alto que foi de ${ }^{2} \$ 90,00$ em 2015 , ou seja, com a variação nos preços da energia estabelecidos nos leilões o projeto pode se tornar inviável. Os parâmetros investimento e o preço do crédito de carbono não inviabilizam o projeto quando seus valores são variados em $50 \%$. O investimento inicial apresentou VPL de $\$ 460.530,97$ no caso de um aumento de $50 \%$, enquanto que uma diminuição de $50 \%$ no preço da tonelada de carbono acarretaria um VPL de $\$ 440.784,49$. O valor mínimo para o preço da tonelada de carbono, onde torna o VPL igual a zero é $\$ 1,04$, por tanto caso o projeto não comercialize os créditos de carbono, o projeto se torna inviável apresentando VPL igual a $(\$ 288.214,33)$.

\footnotetext{
${ }^{1}$ Cotação do dólar na data 17/02/2017: \$3,0499.
} 


\section{CONCLUSÃO}

Este artigo é um estudo preliminar da possibilidade da geração de energia elétrica a partir do uso do biogás gerado em aterro sanitário hipotético para cidade de Varginha. Durante os 20 anos de funcionamento do aterro, este receberia em média 701,84 t/dia e geraria anualmente 1,32 MW, potência suficiente para o abastecimento de mais de 4.000 residências. Considerando os parâmetros adotados, o empreendimento é viável (VPL>0), porém é dependente do preço da energia elétrica e depende fortemente da comercialização dos créditos de carbono, que caso não ocorra, torna o investimento inviável.

De maneira geral, o uso do biogás é uma alternativa para diversificar a geração de energia através de uma fonte renovável e seu uso traz a possibilidade da geração descentralizada de energia. A geração de energia a partir do biogás apresenta como vantagens o aproveitamento energético dos resíduos sólidos urbanos, uma vez que grande parte do lixo no Brasil é destinado aos aterros, e ainda traz a possibilidade da redução de gases de efeito estufa.

\section{REFERÊNCIAS}

ABRELPE. Associação Brasileira de Empresas de Limpeza Pública e Resíduos Especiais. Panorama dos Resíduos Sólidos no Brasil. São Paulo: 2015.

ANEEL. Agência Nacional de Energia Elétrica. Resultado dos leilões de geração. Brasília: 2016.

BARROS, R. M.. Tratado sobre resíduos sólidos: gestão, uso e sustentabilidade. Rio de Janeiro: Interciência, 2012

BORBA, S. M. P.. Análise de modelos de geração de gases em aterros sanitários: estudo de caso. Dissertação (Mestrado em Ciências em Engenharia Civil) - Universidade Federal do Rio de Janeiro, Rio de Janeiro, 2006.

CETESB. Companhia Ambiental do Estado de São Paulo. Biogás, geração e uso energético: aterros. São Paulo: CETESB, 2006.

EPE. Empresa de Pesquisa Energética. Avaliação Preliminar do Aproveitamento Energético dos Resíduos Sólidos Urbanos de Campo Grande/MS. Rio de Janeiro, EPE, 2008.

FERREIRA, R. C.. Plano Municipal de Gestão Integrada de Resíduos Sólidos. Varginha, 2013.

GONÇALVES, M. A.; TANAKA, A. N.; AMEDOMAR, A. A. A. Destinação final dos resíduos sólidos urbanos: alternativas para a cidade de São Paulo através de casos de sucesso. Future Studies Research Journal: Trends and Strategies. São Paulo, v.5, n.1, 2013.

ICLEI. Governos Locais pela Sustentabilidade. Manual para aproveitamento do biogás: efluentes urbanos. São Paulo: 2010.

MONTEIRO, J. H. P.. Manual de gerenciamento integrado de resíduos sólidos. Rio de Janeiro: IBAM, 2001.

QASIN, S. R.. Wastewater Treatment Plants: Planninng design and operation. 2 ed. Lancaster: Technomic Publishing Company, 1999.
RODRIGUES, T. S. N.. Estudo de viabilidade do aproveitamento energético do biogás gerado em célula experimental no aterro controlado da Muribeca Pernambuco (PE). Dissertação (Mestrado Engenharia Civil) Universidade Federal de Pernambuco, Recife, 2009.

SOUZA, G.. Monitoramento de Parâmetros qualitativos e quantitativos de líquidos percolados de aterro sanitários: estudo em piloto experimental. Dissertação - Universidade Federal de Santa Catarina, Florianópolis, 2005.

SOUZA, J. S.. Análise crítica sobre técnicas de avaliação de investimentos mais utilizados pelas empresas. In: Encontro Nacional de Engenharia de Produção, 27. Anais. Foz do Iguaçu: 2007.

TCHOBANGLOUS, G.; THEISEN, H.; VIGIL, S.. Integrated Solid Waste Management Engineering Principles and Management Issues. New York: McGrall-Hill, 1993.

USEPA. United States Environmental Protection Agency. Landfill Gas Emissions Model. New York: 2005.

VON SPERLING, M.. Introdução à qualidade das águas e ao tratamento e esgotos. 2 ed. Belo Horizonte: UFMG, 2005. 